\title{
1 Discovery and Characterization of Novel Lignocellulose-Degrading Enzymes from the
}

\section{Porcupine Microbiome by Synthetic Metagenomics}

3 Mackenzie Thornbury ${ }^{1, \dagger}$, Jacob Sicheri ${ }^{1, \dagger}$, Patrick Slaine ${ }^{1}$, Landon J. Getz ${ }^{1}$, Emma Finlayson-

4 Trick $^{1}$, Jamie Cook $^{1}$, Caroline Guinard ${ }^{1}$, Nicholas Boudreau ${ }^{1}$, David Jakeman ${ }^{2,3}$, John Rohde ${ }^{1}$,

5 Craig McCormick ${ }^{1, *}$

6

$7{ }^{1}$ Department of Microbiology and Immunology, Dalhousie University, 5850 College Street,

8 Halifax, Nova Scotia, Canada B3H 4R2

$9{ }^{2}$ Department of Chemistry, Dalhousie University, 6274 Coburg Road, Halifax, Nova Scotia,

10 Canada B3H 4R2

$11{ }^{3}$ College of Pharmacy, Dalhousie University, 5968 College Street, Halifax, Nova Scotia, Canada

12 B3H 4R2

16 Corresponding author: C.M., craig.mccormick@ dal.ca

$17 \dagger$ Co-first authors

18 Running Title: Lignocellulose-degrading enzymes from the porcupine microbiome

19 Keywords: microbiome, porcupine, synthetic metagenomics, enzyme, lignocellulose,

20 hemicellulose; endoxylanase 


\section{Abstract}

25 Plant cell walls are composed of cellulose, hemicellulose, and lignin, collectively known as

26 lignocellulose. Microorganisms degrade lignocellulose to liberate sugars to meet metabolic

27 demands. Using a metagenomic sequencing approach, we previously demonstrated that

28 the microbiome of the North American porcupine (Erethizon dorsatum) is replete with

29 lignocellulose-degrading enzymes. Here, we report the identification, synthesis and

30 partial characterization of four novel genes from the porcupine microbiome encoding putative

31 lignocellulose-degrading enzymes; $\beta$-glucosidase, ?-L-arabinofuranosidase, $\beta$-xylosidase, and an

32 endo-1,4- $\beta$-xylanase. These genes were identified via conserved catalytic domains associated

33 with cellulose- and hemicellulose-degradation, and phylogenetic trees were created to depict

34 relatedness to known enzymes. The candidate synthesized genes were cloned into the pET26b(+)

35 plasmid to enable inducible expression in Escherichia coli (E. coli). Each candidate gene was

36 cloned as a fusion protein bearing an amino-terminal PelB motif required for periplasmic

37 localization and subsequent secretion, and a carboxy-terminal hexahistidine (6xHIS) tag to

enable affinity purification. We demonstrated IPTG-inducible accumulation of all four fusion

proteins. The putative $\beta$-glucosidase fusion protein was efficiently secreted but did not permit $E$.

coli to use cellobiose as a sole carbon source, nor did the affinity purified enzyme cleave $p$ -

41 Nitrophenyl $\beta$-D-glucopyranoside ( $p$-NPG) substrate in vitro over a range of physiological $\mathrm{pH}$

42 levels ( $\mathrm{pH}$ 5-7). By contrast, the affinity purified putative endo-1,4- $\beta$-xylanase protein cleaved a

43 6-chloro-4-methylumbelliferyl xylobioside substrate over this same $\mathrm{pH}$ range, with maximal

44 activity at $\mathrm{pH}$ 7. At this optimal $\mathrm{pH}, K_{\mathrm{M}}, \mathrm{V}_{\max }$, and $k_{\text {cat }}$ were determined to be $32.005 \pm 4.72 \mu \mathrm{M}$,

$451.16 \times 10^{-5} \pm 3.55 \times 10^{-7} \mathrm{M} / \mathrm{s}$, and $94.72 \mathrm{~s}^{-1}$, respectively. Thus, our synthetic metagenomic pipeline

46 enabled successful identification and characterization of a novel hemicellulose-degrading 
47 enzyme from the porcupine microbiome. Progress towards the goal of introducing a complete

48 lignocellulose-degradation pathway into $E$. coli will be accelerated by combining synthetic

49 metagenomic approaches with functional metagenomic library screening, which can identify

50 novel enzymes unrelated to those found in available databases.

\section{Author summary}

52 Plants depend on a mixture of complex polysaccharides including cellulose, hemicellulose and

53 lignin to provide structural support. Microorganisms use enzymes to break down these

54 polysaccharides into simple sugars like glucose that they burn for energy. These microbial

55 enzymes have the potential to be repurposed for industrial biofuel production. Previously, we

56 showed that bacteria in the porcupine gut produce enzymes that break down cellulose and

57 hemicellulose. Here we report the identification and synthesis of four genes from the porcupine

58 microbiome that encode enzymes that can break down complex plant polysaccharides, including

59 a $\beta$-glucosidase, an ?-L-arabinofuranosidase, a $\beta$-xylosidase, and an endo-1,4- $\beta$-xylanase. These

60 genes were introduced into the model bacterium Escherichia coli (E. coli) to test the properties

61 of their respective gene products. All four enzymes accumulated following the induction of gene

62 expression, but only the putative cellulose-degrading $\beta$-glucosidase and hemicellulose-degrading

$63 \beta$-xylosidase and ?-L-arabinofuranosidase enzymes were efficiently secreted out of the bacteria

64 where they could access their target polysaccharides. Expression of the putative $\beta$-glucosidase

65 did not allow E. coli to grow on cellobiose as a sole carbon source, and the purified enzyme

66 failed to cleave $p$-NPG in vitro. By contrast, the purified putative endo-1,4- $\beta$-xylanase cleaved an

67 artificial hemicellulose substrate in vitro across a range of acidic and neutral $\mathrm{pH}$ values, with

68 maximal activity at $\mathrm{pH}$ 7. This study demonstrates the power of our approach to identify novel

69 microbial genes that may be useful for industrial biofuel production. 
70

71

72

73

74

75

76

77

78

79

80

81

82

83

84

85

86

87

88

89

90

91

92

\section{Introduction}

The gut microbiome comprises thousands of microbial species encoding millions of genes that affect host physiology [1]. These microbes provide a genetic repository of digestive enzymes that convert complex lignocellulose polymers into simple fermentable sugars [2,3].

This repository of unique enzymes has the potential to be harnessed for industrial purposes [4].

Lignocellulosic biomass consists of cellulose, hemicellulose, and lignin, typically found in a

4:3:3 ratio [3]. Microbial enzymes have been shown to catalyze the degradation of cellulose and

hemicellulose into monosaccharides that can be utilized for the production of ethanol biofuel

$[5,6,7,8]$. However, hemicellulose has not yet been extensively investigated as a biofuel

substrate. Moreover, lignin has a complex chemical structure that impedes chemical and

enzymatic hydrolysis. Wi et al. recently demonstrated a new hydrogen peroxide pre-treatment

that improves downstream biocatalytic hydrolysis of lignocellulose by removing lignin [9].

Overall, microbial lignocellulose-degrading enzymes remain a largely untapped resource for biofuel production.

The North American Porcupine, Erethizon dorsatum, is a hind-gut fermenter with an enlarged cecum packed with microbes that aid digestion of lignified plants, coniferous and deciduous cambium (inner bark), and flowers [10]. Using metagenomic sequencing, the 2016

Dalhousie international Genetically Engineered Machine (iGEM) team determined that the porcupine microbiome is replete with microbial enzymes with potential lignocellulose-degrading properties [11]. Furthermore, using shotgun metagenomic and 16S sequencing, the authors confirmed that host diet influences gut microbial diversity and metabolic function; they reported that herbivores like beavers and porcupines had elevated levels of cellulolytic genes in their microbiomes compared to carnivores like the Arctic wolf and coyote. 
These findings inspired the 2017 Dalhousie iGEM team to continue studying enzymes

94 from the porcupine microbiome with the long-term objective of engineering a novel

95 lignocellulose-degradation pathway in E. coli for biofuel applications. We created our own

96 synthetic metagenomic pipeline to identify and characterize putative cellulose- and

97 hemicellulose-degrading enzymes from existing datasets.

98 Results

99 Identification and Cloning of Putative Microbial Enzymes via a Synthetic Metagenomic Pipeline

101 We used a metagenomic sequencing pipeline (Fig. 1A) to identify four microbial genes from 102 porcupine fecal samples predicted to encode putative cellulose- or hemicellulose-degrading 103 enzymes; a $\beta$-glucosidase, an ?-L-arabinofuranosidase, a $\beta$-xylosidase, and an endo-1,4- $\beta$ 104 xylanase (Figs 1B, 2A). These genes were identified by similarity of predicted primary amino 105 acid sequences to conserved domains from known enzymes found in the Research Collaboratory 106 for Structural Bioinformatics Protein Data Bank (Fig 1B). $\beta$-glucosidase enzymes catalyze the 107 final step in cellulose degradation by converting cellobiose disaccharides to glucose monomers 108 (Fig 2B), whereas ?-L-arabinofuranosidase, $\beta$-xylosidase, and endo-1,4- $\beta$-xylanase catalyze 109 sequential steps in the degradation of hemicellulose to xylose monomers (Fig. 2C). This 110 collection of putative enzymes is insufficient to achieve full degradation of complex 111 lignocellulose substrates, but their synthesis and characterization serves as an important test of 112 our synthetic metagenomic pipeline. 
bioinformatic pipeline (A) began with Illumina MiSeq data previously collected from a

117 porcupine fecal DNA sequencing project [11]. Reads were checked for quality and trimmed, concatemerized via MegaHit [12], and open reading frames were identified using Prodigal [13].

119 Protein sequences of interest were identified by pHMMER [14] using various protein databases and were selected for matches of interest based on e-value selection. (B) Top putative microbial enzymes identified by the metagenomic sequencing pipeline; putative signal sequences are

122 shown in orange and predicted conserved protein domains are shown.

Fig 2. Four putative cellulose-/hemicellulose-degrading enzymes identified from the

porcupine microbiome. A) Functional description of putative enzymes with corresponding e-

values. The e-value is a measure of confidence, with lower values denoting higher confidence.

B) The catabolic pathway that converts cellobiose to glucose C) The catabolic pathway that

127 converts hemicellulose to xylose.

\section{In Silico Analysis of Putative Enzymes}

129 The predicted primary amino acid sequence of each candidate gene was used to query the NCBI 130 non-redundant protein sequence database using the Basic Local Alignment Search Tool 131 (BLAST) [15]. Each of our four putative enzymes from the porcupine microbiome were most 132 closely related to enzymes encoded by anaerobic bacteria. Specifically, our putative $\beta$-xylosidase was $75 \%$ identical (100\% coverage) to a $\beta$-xylosidase from Butyrivibrio sp. CAG:318. Our

134 putative $\beta$-glucosidase was $73 \%$ identical (99\% coverage) to a $\beta$-glucosidase encoded by 135 Bacteroides faecis MAJ27. Our putative ?-L-arabinofuranosidase was 63\% identical (92\% 136 coverage) to a glycosyl hydrolase (GH) family 43 protein encoded by Prevotella sp. CAG:732.

137 The putative endo-1,4- $\beta$-xylanase was $55 \%$ identical (99\% coverage) to a hypothetical protein 
BHV73_02415 encoded by Bacteroides sp. 44_46 and predicted to contain GH10 and GH43 domains.

Phylogenetic analysis of all four putative gene products was performed using the 22 closest homologs for each. The putative endo-1,4- $\beta$-xylanase and $\beta$-glucosidase enzymes clustered closely with their homologs in a clade (Fig 3). These clades were strongly supported by high bootstrap values (100 and 100, respectively) on each node, generated from compiling 100 separate trees. The putative ?-L-arabinofuranosidase did not fall into a clade, but did cluster with

145 its closest homologs, whereas $\beta$-xylosidase clustered poorly. Next, predicted amino acid sequences of all four putative enzymes were aligned with closest homologs to determine

147 conservation of key catalytic residues (Figs S1A-S1D). A key aspartic acid is conserved in the catalytic domain of the putative $\beta$-glucosidase; this residue was conserved across all 22 proteins analyzed, with 4 examples aligned to the putative enzyme in Fig. S1A. By contrast, the catalytic domain of endo-1,4- $\beta$-xylanase consists of two conserved aspartic acids and a glutamic acid; all three residues were perfectly conserved over all 22 proteins analyzed, including the predicted 152 protein, and 4 example sequences were aligned to the putative endo-1,4- $\beta$-xylanase in Fig. S1B. 153 ?-L-arabinofuranosidase similarly has two conserved aspartic acids and a single glutamic acid 154 responsible for activity, that shows perfect conservation against all proteins analyzed (S1B). The putative $\beta$-xylosidase showed low conservation from amino acids $190-230$, but the conserved catalytic domain requiring the two conserved aspartic acids and a single glutamic acid were also

157 found to be conserved across all sequences analyzed. Identifying and confirming the catalytic 158 sites provides evidence that these proteins may function in a biological system and require 159 functional assays to determine activity by de novo synthesis of these open reading frames. 


\section{Fig 3. Phylogenetic analysis of putative enzymes.}

162 Phylogenetic analysis of A) ?-L-arabinofuranosidase, B) $\beta$-glucosidase, C) $\beta$-xylosidase, and D)

163 Endo-1,4- $\beta$-xylanase were created from primary amino acid sequence that were aligned using

164 ClustalW and generated using RAxML 7.2.8. Sequences were taken from highly related proteins

165 from the BLASTP database. Trees were replicated 100 times for statistical strength with

166 bootstrap values presented at each node. Putative enzymes are highlighted in red.

167 Synthesis, Expression and Secretion of Putative Enzymes in E. coli

168 The four putative microbial enzymes were synthesized and cloned into the pET26b(+) vector to enable IPTG-inducible gene expression in E. coli. Because directed secretion of enzymes provides access to extracellular lignocellulosic substrates, each candidate gene was cloned as a

171 fusion protein bearing an amino-terminal PelB motif required for periplasmic localization and 172 subsequent secretion. A hexahistidine (6xHIS) tag was added to carboxy-termini of each fusion 173 protein to enable affinity purification. Log-phase E. coli cultures were treated with IPTG to 174 induce transgene expression, followed by harvest of cell supernatant, periplasm and total cell

175 fractions. Specifically, proteins in the supernatant were harvested by trichloroacetic acid (TCA) 176 precipitation and periplasmic proteins were harvested by cold osmotic extraction as previously

177 described [16]. These fractions were subjected to SDS-PAGE and immunoblotting to detect

178 6XHIS fusion proteins (Fig 4). All four putative enzymes accumulated in the total cell fraction:

$179 \beta$-xylosidase at $\sim 51 \mathrm{kDa}$, endo-1,4- $\beta$-xylanase at $\sim 81 \mathrm{kDa}$, ??-L-arabinofuranosidase at $\sim 61 \mathrm{kDa}$, 180 and $\beta$-glucosidase at $\sim 84 \mathrm{kDa}$ (Fig 4A). Among these putative enzymes, only the endo- $1,4-\beta$ 181 xylanase failed to translocate to the periplasm, and it accumulated in the cell pellet fraction (Figs $1824 \mathrm{~B}, 4 \mathrm{C})$. 
Fig 4. Secretion Assay of Putative Enzymes. Log-phase BL21(DE3) E. coli containing a putative enzyme or empty vector control were treated with $0.1 \mathrm{mM}$ IPTG to induce T7-promoterdependent transcription. After 3 hours, A) cells were lysed, B) cells were treated with cold osmotic shock to extract periplasmic protein fraction, or C) the supernatant was filtered, and protein was precipitated by addition of TCA. All protein fractions were prepared for SDS-PAGE and analyzed by western blot with an anti-His-antibody.

\section{Isolation and Characterization of a Putative $\beta$-glucosidase}

Treatment of transformed log-phase $E$. coli cultures with IPTG caused accumulation of the known beta-glucosidase DesR $[17,18]$ which we isolated by affinity purification and detected by immunoblotting with an anti-6XHIS antibody (Fig 5A). Our putative microbial $\beta$-glucosidase fusion protein also accumulated and was affinity purified (Fig 5B). Consistent with published reports, purified DesR efficiently cleaved a $p$-Nitrophenyl $\beta$-D-glucopyranoside ( $p$-NPG) substrate in vitro at $\mathrm{pH} 7$ (Fig 5C). By contrast, our $\beta$-glucosidase failed to cleave $p$-NPG over a broad $\mathrm{pH}$ range (Fig 5D). Moreover, expression of the putative $\beta$-glucosidase in $E$. coli did not enable growth on cellobiose as a sole carbon source. Taken together, these findings indicate that our putative $\beta$-glucosidase does not function in conventional $\beta$-glucosidase assays.

\section{Fig 5. Purification and Characterization of $\square$-glucosidase}

A) Putative $\square$-glucosidase and positive control $\square$-glucosidase DesR were purified by 6x His purification. Red arrow indicates relevant band B) Activity of putative $\square$-glucosidase against $p$ NPG at pH 5.0, 6.0 and 7.0, plotted with positive control; $\square$-glucosidase DesR at pH 7.0.

\section{Isolation and Characterization of a Putative Endo-1,4- $\beta$-xylanase}

We successfully purified our putative endo-1,4- $\beta$-xylanase using the protein production and isolation protocol described above (Fig 6A). Enzyme activity was assessed using 6-chloro-4- 
methylumbelliferyl xylobioside (CMU- $\left.\mathrm{X}_{2}\right)$ substrate and a modified protocol developed by Hallam and Withers [19]. When cleaved by an active enzyme, CMU is released from xylobiose, causing fluorescence emission. CMU- $\mathrm{X}_{2}(100 \mu \mathrm{M})$ was combined with $0.6 \mu \mathrm{g}$ of purified putative endo-1,4- $\beta$-xylanase over a wide $\mathrm{pH}$ range. Immediately upon addition of enzyme, the fluorophore was excited at $365 \mathrm{~nm}$ and emission was read at $450 \mathrm{~nm}$; one measurement was taken every minute for 30 minutes. The increase in raw fluorescence units (RFUs) over time indicated cleavage of the CMU-X $X_{2}$ substrate by the putative endo-1,4- $\beta$-xylanase; this reaction was catalyzed most efficiently at $\mathrm{pH} 7$ (Fig 6B). The DesR $\beta$-glucosidase served as a negative control in these assays and did not cleave the CMU-X ${ }_{2}$ substrate (Figure S3).

To investigate the thermostability of the putative endo- $1,4-\beta$-xylanase, we incubated samples containing $0.6 \mu \mathrm{g}$ of purified enzyme for 30 minutes at $37 \square, 50^{\circ} \mathrm{C}, 60^{\circ} \mathrm{C}$, or $70^{\circ} \mathrm{C}$ before conducting an in vitro $\mathrm{CMU}-\mathrm{X}_{2}$ cleavage assay as described above. Enzyme activity was abolished after 30-minute incubation at any of these temperatures (Fig 6D). A Michaelis-Menten plot was generated for endo-1,4- $\beta$-xylanase activity over a range of CMU- $\mathrm{X}_{2}$ concentrations (Fig 6 E). From this, kinetic constants for endo-1,4- $\beta$-xylanase were calculated using a LineweaverBurk double reciprocal plot (Fig 6F). Endo-1,4- $\beta$-xylanase had a calculated $K_{\mathrm{M}}$ value of $32.005 \pm$ $4.72 \mu \mathrm{M}$ for CMU- $\mathrm{X}_{2}$ and a $\mathrm{V}_{\max }$ of $1.16 \times 10^{-5} \pm 3.55 \times 10^{-7} \mathrm{M} / \mathrm{s}$. The calculated turnover number ( $\left.k_{\text {cat }}\right)$ for endo-1,4- $\beta$-xylanase was found to be $94.7 \mathrm{~s}^{-1}$. Finally, $k_{\text {cat }} / K_{\mathrm{M}}$ was calculated to be $2.96 \times 10^{6} \mathrm{M}^{-1} \mathrm{~s}^{-1}$.

\section{Fig 6. Characterization of Endo-1,4- $\square$-xylanase}

A) Putative endo-1,4- $\beta$-xylanase was purified by $6 \mathrm{x}$ His purification. B) $0.6 \mu \mathrm{g}$ of endo-1,4- $\beta$ xylanase was combined with $100 \mu \mathrm{M}$ of $\mathrm{CMU}-\mathrm{X}_{2}$ to assess enzyme activity at different $\mathrm{pH}$. Samples were assessed via fluorescence in sodium citrate buffer $(\mathrm{pH} 4,5,5.5,6)$ or sodium 
phosphate buffer ( $\mathrm{pH} 6.5,7,7.5)$. A reading of raw fluorescent units (450 nm) was taken every minute for 30 minutes at $37 \square$. C) Relative activity of endo-1,4- $\beta$-xylanase at different $\mathrm{pH}$ compared to $\mathrm{pH}$ 7. D) Thermostability of endo-1,4- $\beta$-xylanase was assessed. Samples containing $0.6 \mu \mathrm{g}$ of endo-1,4- $\beta$-xylanase in $50 \mathrm{mM}$ sodium phosphate buffer were incubated for 30 minutes at $37 \square, 50 \square, 60 \square$, or $70 \square$ before being introduced to $100 \mu \mathrm{M}$ of CMU-X 2 and read as before.

Control is unincubated endo-1,4- $\beta$-xylanase. E) Michaelis-Menten plot was generated with initial reaction rate against substrate concentrations above at $37 \square, \mathrm{pH} 7$. F) Lineweaver-Burk plot was used to generate kinetic constants $K_{\mathrm{M}}, \mathrm{V}_{\max }$, and $k_{\text {cat }}$.

\section{Discussion}

The Dalhousie 2016 iGEM team previously demonstrated that the porcupine microbiome is a particularly rich source of lignocellulose-degrading enzymes [11]. We developed a synthetic metagenomic pipeline to mine the porcupine microbiome for novel enzymes with useful properties. We used stringent selection criteria to maximize our chances of discovering bona fide cellulose/hemicellulose-degrading enzymes. We identified and synthesized four previously uncharacterized genes encoding putative cellulose- and hemicellulose-degrading enzymes from the porcupine microbiome: a $\beta$-glucosidase, an ?-L-arabinofuranosidase, a $\beta$-xylosidase, and an endo-1,4- $\beta$-xylanase. We thoroughly analyzed these putative enzymes by phylogenetic analysis and identified key conserved residues in proposed catalytic sites. These putative enzymes were affinity purified, and we demonstrated clear in vitro activity of a purified putative endo-1,4- $\beta$ xylanase, with optimal activity at $\mathrm{pH} 7$, consistent with the neutral $\mathrm{pH}$ of the porcupine cecum [20]. This marks the first discovery of a functional hemicellulose-degrading enzyme from the porcupine microbiome, and it demonstrates the power of our synthetic metagenomic approach. 
251 The microbial genome that encodes our novel endo-1,4- $\beta$-xylanase is unknown, but it has a

252 Shine-Dalgarno (SD) Sequence found only in bacterial genes, and phylogenetic analysis revealed

253 that it is most closely related to uncharacterized proteins with glycosyl hydrolase (GH) family 10

254 and 43 domains from Bacteroides sp as described by the Carbohydrate Active Enzymes

255 Database (CAZy, http://www.cazy.org/) [21]. GH10 domains have been linked to endo-1,4- $\beta$ -

256 xylanase, endo-1,3- $\beta$-xylanase, tomatinase and/or xylan endotransglycosylase activity, while

257 GH43 domains are commonly found in $\beta$-xylosidase and/or ?-L-arabinofuranosidase enzymes

258 [21]. Because our candidate endo-1,4- $\beta$-xylanase cleaved a modified xylobiose substrate in vitro,

259 we inferred that the GH10 domain was functional in the context of the affinity-purified fusion

260 protein, despite the addition of an amino-terminal PelB domain and carboxy-terminal 6XHis

261 affinity purification tag. This enzyme displayed activity across a wide range of $\mathrm{pH}$ values $(\mathrm{pH} 4-$

262 7.5), but lacked thermostability, quickly losing activity after 30 min incubation at a range of

263 temperatures as low as $37 \square$, despite the fact that the porcupine deep core body temperature is

264 approximately $37 \square[20,22]$. This thermo-instability makes our novel endo-1,4- $\beta$-xylanase less

265 useful for industrial applications compared to known thermophilic endo-1,4- $\beta$-xylanases [23].

266 Enzyme thermostability can be improved via directed evolution; Stephens et. al. used error-prone

267 PCR to increase endo-1,4- $\beta$-xylanase thermostability, creating a superior variant with a single

268 amino acid substitution [24]. Advances in computational prediction and protein folding models

269 can also inform rational mutagenesis strategies to increase enzyme thermostability [25, 26, 27].

270 Such approaches may be used to enhance the thermostability of our novel endo-1,4- $\beta$-xylanase.

271 We calculated a turnover rate $\left(k_{\mathrm{cat}}\right)$ of $94.7 \mathrm{~s}^{-1}$ for our novel endo-1,4- $\beta$-xylanase, which

272 compares favorably with other known enzymes. Using beechwood xylan as a substrate, He et. al.

273 reported that an endo-1,4- $\beta$-xylanase isolated from the fungus Trichoderma reesei had a 
274 relatively high $k_{\text {cat }}$ of $139.7 \mathrm{~s}^{-1}$ [28]. Using the same substrate, Xu et. al. reported a lower rate of

275 turnover of $47.34 \mathrm{~s}^{-1}$ for a microbial xylanase containing a GH10 family domain isolated from

276 the feces of the black snub-nosed monkey (Rhinopithecus bieti) [29]. A GH11 family endo-1,4-

$277 \beta$-xylanase isolated from the fungus Fusarium oxysporum also had a low rate of turnover $\left(0.27 \mathrm{~s}^{-}\right.$

$278^{1}$ ) of RBB-xylan substrate, a chromogenic derivative of beechwood xylan [30]. Like other kinetic

279 constants, turnover rates are substrate-specific. Because we were the first to use CMU-X 2 to

280 calculate kinetic constants for an endo-1,4- $\beta$-xylanase, we cannot directly compare our findings

281 to studies that employ beechwood xylan or RBB-xylan. Future studies should characterize

282 kinetic constants of our endo-1,4- $\beta$-xylanase on more conventional substrates such as

283 beechwood, birchwood, and oat-spelt xylan.

284 Among the other three putative enzymes identified in this study, the $\beta$-glucosidase accumulated 285 to high levels, translocated to the periplasm and was efficiently secreted, yet it lacked in vitro 286 activity. The putative ?-L-arabinofuranosidase was also efficiently secreted, but its enzymatic 287 activity remains to be tested as we seek out appropriate substrates. By contrast, $\beta$-xylosidase was 288 difficult to purify and was often retained in the insoluble pellet fraction. Insolubility can occur 289 when a protein aggregates before it can fold properly [31]. To promote proper folding and solubility of our putative $\beta$-xylosidase, we reduced IPTG levels from $1.0 \mathrm{mM}$ to $0.1 \mathrm{mM}$ and

291 reduced the culture temperature to $20^{\circ} \mathrm{C}$ during the time of induction. Despite these precautions, 292 the amount of affinity purified $\beta$-xylosidase remained insufficient for subsequent in vitro enzyme 293 assays. It is possible that $E$. coli lacks appropriate chaperone activity required to efficiently fold 294 this enzyme.

295 Our synthetic metagenomic pipeline is a powerful tool for discovery, but because it infers 296 functional relationships from homology to previously characterized sequences in a database, it 
297 will likely fail to identify greatly divergent proteins with desirable properties. It may also

298 identify putative enzymes that appear to have conserved functional domains, but lack the

299 function predicted by homology. By contrast, functional metagenomic library screens rely on

300 functional assays for gene discovery. Thus, functional metagenomics provides a convenient

301 approach to new gene discovery that nicely complements sequence-based approaches, but with

302 greater potential for discovery of truly novel genes that don't resemble those in existing

303 databases. Recently, using functional metagenomics, Cheng, et. al. discovered three novel $\beta$ -

304 galactosidase enzymes, two of which had conserved domains, and one of which was part of a

305 previously undiscovered enzyme family [32]. To complement our synthetic metagenomics

306 approach, we plan to create and screen a functional metagenomic library from porcupine

307 microbiome DNA to discover novel lignocellulose-degrading enzymes.

\section{Materials and Methods}

\section{Identification of Open Reading Frames}

310 Metagenomic analysis of Illumina MiSeq data was conducted using our previously published

311 protocols [11]. FASTQC and BowTie2 were used to inspect reads for overall quality and

312 contaminants from sequencing. Reads were trimmed to $400 \mathrm{bp}$ in length to remove low-quality

313 terminal sequences from further analysis. MegaHIT alignment software processed reads in

314 FASTq format and stitched reads into longer contigs by identifying overlapping coding regions

315 [12]. Prodigal was used to identify open reading frames (ORFs) by searching sequences in six

316 frames across both DNA strands [13]. A '-c' command modifier in Prodigal was used to ensure

317 the program only detected ORFs with both start and stop codons present. Prodigal was instructed

318 to search for Shine-Dalgarno sequences required for ribosome binding to prokaryotic mRNAs,

319 and non-canonical start codons CUG, GUG and ACG which are typically found in up to $10 \%$ of 
320 prokaryotic ORFs; these products are often overlooked by conventional searches and absent from

321 many databases [33,34]. These restrictions were expected to limit our hits to prokaryotic genes,

322 rather than genes from eukaryotes like fungi and protists that lack Shine-Dalgarno sequences.

\section{In Silico Protein Function Predictions}

324 pHmmer was used to identify putative function of protein domains $[14,35]$. Protein domains and

325 possible functions were identified using the Research Collaboratory for Structural Bioinformatics

326 Protein Data Bank [36]. e-values were calculated to compare domains identified in putative

327 proteins to known domains in the database [36]. Putative proteins with the lowest e-values were

328 queried against the Basic Local Alignment Search Tool (BLAST) database using pHmmer to

329 identify proteins with major protein domain conservation. Selected candidate genes were codon-

330 optimized for E. coli and synthesized by Integrated DNA Technologies (IDT, Coralville, IA,

331 USA) as gBlock gene fragments.

332 Amino acid sequence analysis

333 Phylogenetic trees were generated and interpreted in Geneious R 8.1.8. using RAxML version

3347.2 .8 with the protein model GAMMA LG (algorithm: Rapid bootstrapping with 100 replicate

335 trees for statistical power) [37].

336 Amino acid alignments were completed using ClustalW alignment with the cost matrix:

337 BLOSUM with a gap open cost of 10 and a gap extend cost of 0.1 [38].

338 Putative genes were submitted to GenBank with the accession numbers as follows: $\beta$ -

339 Glucosidase MH590637, $\alpha$-L-arabinofuranosidase MH590638, $\beta$-xylosidase MH590639, Endo-

$340 \quad$ 1,4- $\beta$-xylanase MH590640.

341 Gene Cloning 
342 Candidate genes were PCR-amplified from IDT gBlock gene fragments with Phusion High-

343 Fidelity DNA Polymerase according to manufacturer's instructions (New England Biolabs

344 (NEB), Ipswich, MA, USA). PCR products were purified using the QIAquick gel extraction kit

345 protocol (Qiagen Inc., Toronto, ON, Canada) (Table 1) and cloned into the pET26b(+)

346 expression plasmid (MilliporeSigma); this plasmid enables the creation of fusion proteins with

347 PelB leader sequences required for translocation to the periplasm after which they can be

348 secreted into the extracellular space [39]. Thus, by fusing our putative enzymes to PelB we

349 increased the likelihood of secretion to the extracellular space to access lignocellulosic

350 substrates. Candidate genes and pET26b(+) were digested with restriction endonucleases (NEB)

351 indicated in Table 1 for 1 hour at 37 ?. Digested DNA was subjected to agarose gel

352 electrophoresis on a $0.8 \%$ agarose gel and purified using the QIAquick gel extraction kit

353 according to manufacturer's instructions (Qiagen Inc.), then ligated with pET26b(+) plasmid

354 DNA using T4 DNA ligase (NEB). Ligation products were transformed into chemically

355 competent Stbl3 E. coli via heat-shock transformation [40]. Specifically, $5 \mu \mathrm{L}$ of ligation

356 products were added to $50 \mu \mathrm{L}$ of $E$. coli suspension in Luria-Bertani (LB) broth, and following

357 heat-shock transformation, $250 \mu \mathrm{L}$ of LB broth was added during the 1 hour recovery stage and

358 the mixture was subsequently plated on LB agar $+25 \mu \mathrm{g} / \mathrm{ml}$ kanamycin. Plates were incubated at

$35937{ }^{\circ} \mathrm{C}$ for $18-24$ hours to allow the growth of transformants. Colonies were picked and inoculated

360 into $5 \mathrm{~mL}$ of LB broth, grown overnight to saturation, and plasmid DNA was extracted via

361 QIAprep Spin Miniprep Kit (Qiagen, Inc.). Plasmids were screened by restriction digestion, and 


\begin{tabular}{|c|c|c|c|}
\hline Putative Enzyme & Forward Primer & Reverse Primer & $\begin{array}{l}\text { Restriction Enzymes } \\
\text { for insertion into } \\
\text { pET26b }(+)\left(5^{\prime}-3^{\prime}\right)\end{array}$ \\
\hline$\beta$-xylosidase & $\begin{array}{l}\text { AAAAAAGGATCCTATG } \\
\text { GCTAACCCGTACTTACCTG }\end{array}$ & $\begin{array}{l}\text { AAAAAAGAGCTCAT } \\
\text { TACTTGGTAAACACG } \\
\text { AACGCC }\end{array}$ & BamHI/Sacl \\
\hline Endo-1,4- $\beta$-xylanase & $\begin{array}{l}\text { GAATTCTGGATCCAATGA } \\
\text { TCAATAAATTACTGTCATC } \\
\text { GGCATTGGCA }\end{array}$ & $\begin{array}{l}\text { AAAAAACTGCAGCAT } \\
\text { AGCGGCCGCTGAGC } \\
\text { TCTTAAGCTT }\end{array}$ & BamHI/Notl \\
\hline$\alpha$-L-Arabinofuranosidase & $\begin{array}{l}\text { GAATTCTGGATCCAATG } \\
\text { GGTCTTGCTATCG }\end{array}$ & $\begin{array}{l}\text { AAAAAACTGCAGCA } \\
\text { TAGCGGCCGCTGAG } \\
\text { CTCTTCTGAG }\end{array}$ & BamHI/Notl \\
\hline$\beta$-Glucosidase & $\begin{array}{l}\text { GAATTCAAGGATCC } \\
\text { AATGAACAAGACCCAC }\end{array}$ & $\begin{array}{l}\text { AAAAAACTGCAGCA } \\
\text { TAGCGGCCGCTGAG } \\
\text { CTCTTAAGCTT }\end{array}$ & BamHI/Notl \\
\hline
\end{tabular}

367 The pET26b(+) vector contains a 6xHIS tag C terminal of the multiple cloning site (MCS).

368 Initially, the candidate genes were cloned with a stop codon interrupting the 6xHIS tag. Site

369 directed mutagenesis was used to delete the stop codon, restoring the C-terminal tag. The

370 constructs were amplified using Phusion High-Fidelity DNA Polymerase according to

371 manufacturer's instructions (NEB). A small portion of PCR product was ran on a $0.8 \%$ agarose

372 gel to confirm size. Once confirmed for proper size, the PCR product was purified with

373 QIAquick PCR Purification Kit according to manufacturer's instructions (Qiagen). After

374 purification, the $6 x \mathrm{HIS}$ tagged constructs were ligated using T4 DNA ligase for $1 \mathrm{hr}$ at $37^{\circ} \mathrm{C}$

375 (NEB).

376 Inducible Protein Expression

377 All pET26b(+) 6xHIS tagged candidate genes were transformed into BL21(DE3) E. coli to

378 enable inducible protein expression. Selected colonies were inoculated into $5 \mathrm{~mL}$ of LB broth

379 and incubated at $37^{\circ} \mathrm{C}$ in a shaker (220 RPM) overnight. The overnight culture was diluted 1:100

380 in $2.5 \mathrm{~mL} \mathrm{LB}$ broth and incubated in a shaker until the $\mathrm{OD}_{600}$ of the culture reached 0.5-0.8. 
381

382

383

384

385

386

387

388

389

390

391

392

393

394

395

396

397

398

399

400

401

402

403

Once in log phase, $0.1 \mathrm{mM}$ IPTG (Thermo Fisher Scientific, Waltham, MA, USA) was added to induce protein expression. After 3 hours of shaking incubation at $37^{\circ} \mathrm{C}$, bacteria were spun at $16000 \mathrm{xg}$ for $2 \mathrm{~min}$, supernatant was collected, and pellets were harvested in 2x electrophoresis sample buffer (ESB) or subjected to periplasmic fractionation. Protein was collected from the supernatant as previously described by Sarty et al. with some modification [41]. Specifically, 2.5 $\mathrm{mL}$ of clarified supernatant was passed through $0.2 \mu \mathrm{m}$ PEL syringe filter and place on ice for 10 min before trichloroacetic acid precipitation. The periplasmic fraction was isolated using previously described cold osmotic shock [16]. Briefly, after the bacteria were pelleted, supernatant was removed, and the pellet was resuspended in $625 \mu \mathrm{L}$ Cell Fractionation Buffer 1 (0.2 M Tris- $\mathrm{HCl}$ (pH 8.0), $200 \mathrm{~g} / \mathrm{L}$ sucrose, 0.1 M EDTA) then incubated at $4{ }^{\circ} \mathrm{C}$ for 20 min with regular inversion. After incubation, the suspension was centrifuged at $16000 \mathrm{xg}$ for $15 \mathrm{~min}$ at 4 ${ }^{\circ} \mathrm{C}$ and supernatant was discarded. The pellet was resuspended in $625 \mu \mathrm{L}$ Cell Fractionation Buffer 2 (0.1 M Tris-HCl (pH 8.0), 0.005 $\mathrm{M} \mathrm{MgSO}_{4}, 0.2 \%$ SDS, $1 \%$ Triton X-100) and incubated for $20 \mathrm{~min}$ at $4{ }^{\circ} \mathrm{C}$ with regular inversion. The suspension was centrifuged as before, and the supernatant was collected as the periplasmic fraction. TCA precipitation was done to concentrate the protein. The vector pET26b(+) (EV) was used as a negative control. Proteins were separated by SDS-PAGE and transferred to PDVF and for western blot analysis using mouse penta HIS antibody (Qiagen, Cat. 34660).

\section{Protein Purification}

Recombinant strains pET26b(+)-endo-1,4- $\beta$-xylanase and pET26b(+)- $\beta$-glucosidase were grown in $5 \mathrm{~mL} \mathrm{LB}$ broth with $25 \mu \mathrm{g} / \mathrm{mL}$ kanamycin from $6 \mathrm{hrs}$ at $37^{\circ} \mathrm{C}$, shaking, from a single clone.

After initial incubation, $1 \mathrm{~mL}$ of culture was used to inoculate $100 \mathrm{~mL}$ of fresh $\mathrm{LB}$ broth with $25 \mu \mathrm{g} / \mathrm{mL}$ kanamycin and $1 \mathrm{mM}$ IPTG for overnight induction at $30^{\circ} \mathrm{C}$, shaking. After induction, 
404

405

406

407

408

409

410

411

412

413

414

415

416

417

418

419

420

421

422

423

424

425

426

the cultures were centrifuged at $3220 \mathrm{xg}$ for $20 \mathrm{~min}$ and supernatant was decanted from pellet. The cell pellets were resuspended in Wash Buffer $\left(20 \mathrm{mM} \mathrm{Na}_{2} \mathrm{PO}_{4}, 500 \mathrm{mM} \mathrm{NaCl}, \mathrm{pH}\right.$ 8.0) and sonicated for a total of $6 \mathrm{~min}$ in $30 \mathrm{sec}$ intervals on ice, then centrifuged at $8000 \mathrm{xg}$ for $30 \mathrm{~min}$ at $4{ }^{\circ} \mathrm{C}$. Subsequently, supernatant was loaded into a column containing HisPur Cobalt Resin (Thermofisher) pre-equilibrated with Wash Buffer. The column was washed with 6 volumes of Wash Buffer, then protein was eluted in Elution Buffer (150 mM imidazole, $20 \mathrm{mM} \mathrm{Na} 2 \mathrm{PO}_{4}, 500$ $\mathrm{mM} \mathrm{NaCl}, \mathrm{pH} 8.0$ ). Glycerol was added to the purified protein at a final concentration of $10 \%$ to maintain protein folding.

Recombinant strain pET26b(+)- $\beta$-xylosidase was difficult to purify and a specialized protocol was used as previously described by Zimmermann et al [42]. Briefly, 1L of LB broth (no antibiotic) was inoculated with $5 \mathrm{~mL}$ of overnight pET26b(+)- $\beta$-xylosidase culture (containing kanamycin). The culture was shaken at $37{ }^{\circ} \mathrm{C}$ at $220 \mathrm{rpm}$ until the $\mathrm{OD}_{600}$ was between 0.4 and 0.7. Once an appropriate density was reached, the culture was incubated at $42{ }^{\circ} \mathrm{C}$ for $10 \mathrm{~min}$, recovered at $37{ }^{\circ} \mathrm{C}$ for $20 \mathrm{~min}$, placed on ice for $30 \mathrm{~min}$, and recovered again at $37{ }^{\circ} \mathrm{C}$ for $30 \mathrm{~min}$.

Once heat- and cold-shocked, the culture was induced with $0.1 \mathrm{mM}$ IPTG and incubated overnight at $20{ }^{\circ} \mathrm{C}$ shaking. The following morning the culture was centrifuged and purified as described above.

\section{In vitro Activity Assays}

The activity of $\beta$-xylosidase and $\beta$-glucosidase was tested using $p$-nitrophenol (pNP) derivatives: $p \mathrm{NP}-\beta$-d-xylopyranoside and $p \mathrm{NP}-\beta$-d-glucopyranoside, respectively. When cleaved by active enzyme, these compounds release pNP which can be measured by absorbance at $410 \mathrm{~nm}$.

General experimental procedure combined $900 \mu \mathrm{L}$ of $5 \mathrm{mM}$ pNP derivative in appropriate buffer, which was used to blank the spectrophotometer (Nanodrop One, Thermo Scientific), once 
$427100 \mu \mathrm{L}$ of appropriately diluted enzyme was added, the absorbance was measured at $410 \mathrm{~nm}$

428 every minute for $30 \mathrm{~min}$. Optimum $\mathrm{pH}$ was determined by using three different buffers (50 $\mathrm{mM})$

429 at $\mathrm{pH}$ 5: citrate buffer, $\mathrm{pH}$ 6: phosphate buffer, and $\mathrm{pH}$ 7: phosphate buffer.

430 The enzymatic activity of endo-1,4- $\beta$-xylanase was determined using 6-chloro-4-

431 methylumbelliferyl xylobioside $\left(\mathrm{CMU}-\mathrm{X}_{2}\right)$. When cleaved by an active enzyme, 6-chloro-4-

432 methylumbelliferyl is released from xylobiose and fluoresces at $450 \mathrm{~nm}$. One hundred

433 micromolar of CMU-X 2 was added to $0.6 \mu \mathrm{g}$ of HIS-purified endo-1,4- $\beta$-xylanase in $50 \mathrm{mM}$

434 sodium citrate buffer $(\mathrm{pH} 4,5,5.5,6)$ or sodium phosphate buffer $(\mathrm{pH} 6.5,7,7.5)$ in a 96-well

435 plate (Grenier). Fluorescence was measured (Ex. 365, Em. 450) at 37? using a plate reader

436 (Molecular Devices SpectraMax M2) immediately and every minute for 30 minutes to determine

437 optimal $\mathrm{pH}$ for enzyme efficiency. Fluorescence at optimal $\mathrm{pH}$ was then compared to a

438 commercial $\beta$-glucosidase (DesR) as a negative control as above. Thermostability of the putative

439 endo-1,4- $\beta$-xylanase was determined by incubating samples containing $0.6 \mu \mathrm{g}$ of enzyme for 30

$440 \quad$ minutes at $37 \square, 50 \square, 60 \square$, or $70 \square$ prior to addition of CMU-X 2 . Samples were then read as

441 before. Control is unincubated endo-1,4- $\beta$-xylanase. To calculate kinetic constants, initial rate of

442 product formation (cleavage of CMU from xylobiose) was calculated for $0.6 \mu \mathrm{g}$ of endo-1,4- $\beta$ -

443 xylanase at differing concentrations of $\mathrm{CMU}_{-} \mathrm{X}_{2}(10 \mu \mathrm{M}, 15 \mu \mathrm{M}, 20 \mu \mathrm{M}, 40 \mu \mathrm{M}, 100 \mu \mathrm{M}, 150$

$444 \mu \mathrm{M}, 200 \mu \mathrm{M}, 250 \mu \mathrm{M})$. Kinetic constants $K_{\mathrm{M}}$ and $k_{\text {cat }}$ of the putative endo-1,4- $\beta$-xylanase were

445 determined using a Lineweaver-Burk plot.

\section{$446 \quad$ Plate Assay}

447 BL21 E. coli containing pET26b(+)- $\beta$-glucosidase, empty pET26b(+) (negative control), or

448 positive control pET28b(+)-DesR [14] were grown overnight in $5 \mathrm{~mL} \mathrm{LB}$ broth with kanamycin

$449(50 \mathrm{ug} / \mathrm{ml})$ at $37^{\circ} \mathrm{C}$, shaking. The next day, $1 \mathrm{ml}$ of overnight culture was added to $4 \mathrm{~mL}$ of fresh 
450 LB and kanamycin. The bacteria were induced with $1 \mathrm{mM}$ IPTG for four hours at $37^{\circ} \mathrm{C}$, shaking.

451 Then, $1 \mathrm{ml}$ of culture was plated on cellobiose M9 media (33.7 mM Na2HPO4, $22 \mathrm{mM}$

$452 \mathrm{KH} 2 \mathrm{PO} 4,8.55 \mathrm{mM} \mathrm{NaCL}, 9.35 \mathrm{mM} \mathrm{NH} 4 \mathrm{Cl}, 12 \%$ cellobiose, $1 \mathrm{mM} \mathrm{MgSO} 4$, and $0.03 \mathrm{mM}$

$453 \mathrm{CaCl} 2$ ) and incubated overnight at $37^{\circ} \mathrm{C}$. Colony growth was observed the following day.

454 Acknowledgements

455 We thank Chris Fetter (Dalhousie U.) for guidance in enzyme kinetics calculations. We thank

456 Drs. Steven Hallam and Steve Withers (UBC) for the generous gift of CMU-X 2 substrate. We

457 thank Zack Armstrong (UBC) for help with troubleshooting enzyme assays and manuscript pre-

458 review. We thank all of the members and mentors of the 2016 and 2017 Dalhousie iGEM teams

459 who launched the porcupine microbiome studies that formed the foundation for the current study.

460

461

462 References

463 1. Shreiner AB, Kao JY, Young VB. The gut microbiom in health and disease. Curr Opin

$464 \quad$ Gasteroenterol. 2015 Jan;31(1):69-75. DOI: 10.1097/MOG.0000000000000139

465 2. Gruninger RJ, McAllister TA, Forester RJ. Bacterial and archaeal diversity in the

466 gastrointestinal tract of the North American beaver (Castor canadensis). PLoS One.

$467 \quad 2016 ; 11(5): \mathrm{e} 0156457$.

468 3. Hongzhang C. Biotechnology of Lignocellulose: Theory and Practice. [Internet]. 1st ed.

469 Dordrecht: Springer Netherlands; c2014. Available from:

470 http://www.springer.com/gp/book/9789400768970. DOI: 10.1007/978-94-007-6898-7 
471 4. Hasunuma T, Okazaki F, Okai N, Hara KY, Ishii J, Kondo A. A review of enzymes and microbes for lignocellulosic biorefinery and the possibility of their application to consolidated bioprocessing technology. Bioresour Technol. 2013 May 1;135:513-22.

474 5. Arfi Y, Shamshoum M, Rogachev I, Peleg Y, Bayer EA. Integration of bacterial lytic polysaccharide monooxygenases into designer cellulosomes promotes enhanced cellulose degradation. Proc Natl Acad Sci. 2014 June;111(25):9109-9114. DOI:10.1073/pnas.1404148111

6. Coughlan MP. Mechansims of cellulose degradation by fungi and bacteria. Anim Feed Sci. 1991 Jan;32(1-3):77-100. DOI: 10.1016/0377-8401(91)90012-H

7. Beeson WT, Vu VV, Span EA, Phillips CM, Marletta MA. Cellulose degradation by polysaccharide monooxygenases. Annu Rev Biochem. 2015 June;84(1):923-946. DOI:

8. Dodd D, Cann IK. Enzymatic deconstruction of xylan for biofuel production. GCB Bioenergy. 2009 Feb 1;1(1):2-17.

9. Wi SG, Cho EJ, Lee DS, Lee SJ, Lee YJ, Bae HJ. Lignocellulose conversion for biofuel: a new pretreatment greatly improves downstream biocatalytic hydrolysis of various Wildlife. Available from: http://www3.northern.edu/natsource/MAMMALS/Porcup1.htm. microbiomes drive cellulolytic enzymatic potential within hind-gut fermenting mammals. PloS one. 2017 Dec 27;12(12):e0189404 
12. Li D, Liu CM, Luo R, Sadakane K, Lam TW. MEGAHIT: an ultra-fast single-node solution for large and complex metagenomics assembly via succinct de Bruijn graph. Bioinformatics. May 2015;31(10):1674-6.

13. Hyatt D, Chen WL, LoCascio PF, Miriam L, Larimer FW, Hauser LJ. Prodigal: prokaryotic gene recognition and translation initiation site identification. BMC Bioinformatics. 2010 Mar $8 ; 11: 119$.

14. Finn RD, Clements J, Eddy SR. (2011). HMMER web server: interactive sequence similarity searching. J Nucleic Acids. 2011 Jul;39:W29-W37

501

502

503

504

505

506
15. Altschul SF, Gish W, Miller W, Myers EW, Lipman DJ. Basic local alignment search tool. Biochem. Mol. Biol. J. 1990 Oct 5;215(3): 403-10.

16. Neu HC, Heppel LA. The release of enzymes from Escherichia coli by osmotic shock and during the formation of spheroplasts. J Biol Chem. 1965 Sept;240(9):3685-3692.

17. Zhao L, Beyer NJ, Borisova SA, Lui H. $\beta$-Glucosylation as a part of self-resistance mechanism in methymycin/pikromycin producing strain Streptomyces venezuelae. Biochemistry. 2003 Aug;42:14794-14804.

18. Sadeghi-Khomami A, Lumsden MD, Jakeman DL. Glycosidase inhibition by macrolide antibiotics elucidated by STD-NMR spectroscopy. Chem Biol. 2008 Jul;15(7):739-749

19. Chen HM, Armstrong Z, Hallam SJ, Withers SG. Synthesis and evaluation of a series of 6chloro-4-methylumbelliferyl glycosides as fluorogenic reagents for screening metagenomic libraries for glycosidase activity. Carbohydr Res. 2016 Feb 8;421:33-39

20. Vispo C, Hume ID. The digestive tract and digestive function in the North American porcupine and beaver. Can J Zool. 1995; 73(5): 967-974 
21. Lombard V, Golaconda Ramulu H, Drula E, Coutinho PM, Henrissat B. The Carbohydrateactive enzymes database (CAZy) 2013. Nucleic Acids Res. 2014;42:D490-D495

22. DeMatteo KE, Harlow HJ. Thermoregulatory responses of the North American porcupine (Erethizon dorsatum bruneri) to decreasing ambient temperature and increasing wind speed. Comp. Biochem. Physiol. B, Biochem. Mol. Biol. 1997 Mar 1;116(3): 339-46.

23. Yeoman CJ, Han Y, Dodd D, Schroeder CM, Mackie RI, Cann IK. Thermostable enzymes as biocatalysts in the biofuel industry. Advances in applied microbiology 2010 Jan 1. doi:10.1016/S0065-2164(10)70001-0.

24. Stephens DE, Rumbold K, Permaul K, Prior BA, Singh S. Directed evolution of the thermostable xylanase from Thermomyces lanuginosus. J. Biotechnol. 2007 Jan 10;127(3): $348-54$

25. Wijma HJ, Floor RJ, Jekel PA, Baker D, Marrink SJ, Janssen DB. Computationally designed libraries for rapid enzyme stabilization. Protein Eng. Des. Sel. 2014 Feb 1;27(2): 49-58.

26. Ásgeirsson B, Adalbjörnsson BV, Gylfason GA. Engineered disulfide bonds increase activesite local stability and reduce catalytic activity of a cold-adapted alkaline phosphatase. Biochim. Biophys. Acta, Proteins Proteomics. 2007 Jun 1;1774(6): 679-87.

27. Zhang W, Mullaney EJ, Lei XG. Adopting selected hydrogen bonding and ionic interactions from Aspergillus fumigatus phytase structure improves the thermostability of Aspergillus niger PhyA phytase. Appl. Environ. Microbiol. 2007 May 1;73(9): 3069-76.

28. He J, Yu B, Zhang K, Ding X, Chen D. Expression of endo-1, 4-beta-xylanase from Trichoderma reesei in Pichia pastoris and functional characterization of the produced enzyme. BMC Biotechnol. 2009 Dec;9(1): 56. 
29. Xu B, Dai L, Li J, Deng M, Miao H, Zhou J, Mu Y, Wu Q, Tang X, Yang Y, Ding J. Molecular and biochemical characterization of a novel xylanase from Massilia sp. RBM26 isolated from the feces of Rhinopithecus bieti. J. Microbiol. Biotechnol. 2015;26(1): 9-19.

30. Gómez S, Payne AM, Savko M, Fox GC, Shepard WE, Fernandez FJ, Vega MC. Structural and functional characterization of a highly stable endo- $\beta-1,4$-xylanase from Fusarium oxysporum and its development as an efficient immobilized biocatalyst. Biotechnol Biofuels. 2016 Dec;9(1): 191.

31. Marinez-Alonso M, Gonzalez-Montalban N, Garcia-Fruitos E, Villaverde A. Learning about protein solubility from bacterial inclusion bodies. Microb Cell Fact. 2009 Jan;8:4. DOI:

$$
10.1186 / 1475-2859-8-4
$$

32. Cheng J, Romantsov T, Engel K, Doxey AC, Rose DR, Neufield JD, Charles TC. Functional metagenomics reveals novel $\beta$-galactosidases not predictable from gene sequences.PLoS ONE. 2017;12(3): e0172545

33. Kozak M. Initiation of translation in prokaryotes and eukaryotes. Gene. 1999 Jul 8; 234(2): $187-208$

34. Hecht A, Glasgow J, Jaschke PR, Bawazer LA, Munson MS, Cochran JR, Endy D et al. Measurements of translation initiation from all 64 codons in E. coli. Nucleic Acids Res. 2017 Apr 20;45(7):3615-3626

35. Johnson SL, Eddy SR, Portugaly E. Hidden Markov model speed heuristic and iterative HMM search procedure. BMC Bioinformatics. 2010 Aug;11:431.

36. H.M. Berman, J. Westbrook, Z. Feng, G. Gilliland, T.N. Bhat, H. Weissig, I.N. Shindyalov, P.E. Bourne. The Protein Data Bank Nucleic Acids Research. 2000, 28: 235242. www.rcsb.org 
37. Kearse M, Moir R, Wilson A, Stones-Havas S, Cheung M, Sturrock S, Buxton S, et al. Geneious Basic: An integrated and extendable desktop software platform for the organization and analysis of sequence data. Bioinformatics. 2012;28:1647-1649.

38. Larkin MA, Blackshields G, Brown NP, Chenna R, McGettigan PA, McWilliam H, Valentin F, Wallace IM, et al. Clustal W and Clustal X version 2.0. Bioinformatics. 2007;23(21): 2947-2948. doi:10.1093/bioinformatics/btm404

39. Sockolosky JT, Szoka FC. Periplasmic production via the pET expression system of soluble, bioactive human growth hormone. Protein Expr Purif. 2013 Feb;87(2):129-135

40. Froger A, Hall JE. Transformation of plasmid DNA into E. coli using the heat shock method. J Vis Exp. 2007 Aug 1;(6):253. doi:10.3791/253.

41. Sarty D, Baker NT, Thomson EL, Rafuse C, Ebanks RO, Graham LL, Thomas NA. Characterization of the type III secretion associated low calcium response genes of Vibrio parahaemolyticus RIMD2210633. Can J Microbiol. 2012 June;58:1306-1315

42. Zimmermann S, Hall L, Riley S, Sørenson J, Amaro RE, Schnaufer A. A novel highthroughput activity assay for the trypanosoma brucei editosome enzyme REL1 and other RNA ligases. Nucleic Acids Res. 2016 Feb;44(3):e24. DOI:10.1093/nar/gkv938

\section{Supporting Information}

Table S1. NCBI Accession Numbers for sequences related to candidate genes from porcupine microbiome from NCBI database

\section{Figure S1. Alignments}

Putative S1A) Endo-1,4- $\beta$-xylanase, S1B)?-L-arabinofuranosidase, S1C) $\beta$-xylosidase, and S1D) $\beta$-glucosidase proteins were aligned to 4 diverse proteins from different bacterial isolates. 
583 Alignments were completed using ClustalW, and catalytic sites are annotated with a $(*)$ below to

584 highlight key residues.

$585 \quad$ Figure S2. Purification of $\square$-xylosidase

586 A) Putative $\square$-xylosidase was purified by 6xHIS purification. Red arrow indicates relevant band

587 B) Activity of putative $\square$-xylosidase against $p$-NPX at pH 5.0, and, 6.0 and plotted with positive

588 control; commercial $\square$-xylosidase from Selenomonas rutinantium (Megazyme, Ireland).

589 Figure S3. Enzymatic activity of endo-1,4- $\beta$-xylanase versus unrelated $\beta$-glucosidase

590 Enzymatic activity of endo- $1,4-\beta$-xylanase was assessed using cleavage of CMU-X 2 and

591 emission $(450 \mathrm{~nm})$ of CMU at $37 \square, \mathrm{pH} 7$, and compared to negative control $\beta$-glucosidase DesR. 
A.

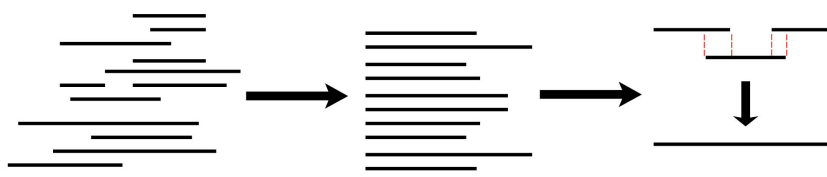

Illumina MiSeq

Data
Quality Checked

Data
Concatemerized

Data

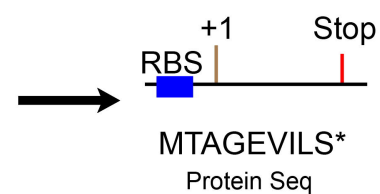

Open Reading Frame Identification

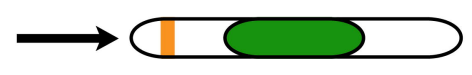

Protein Domain ID

B.

Putative $\alpha$-L-arabinofuranosidase

Glyco Hydrolase Family 43 Domain

Putative $\beta$-xylosidase

Glyco Hydrolase

Family 43 Domain
Putative $\beta$-1,4-endoxylanase

Glyco Hydrolase

Family 10 Domain)

Glyco Hydrolase

Family 43 Domain

Putative $\beta$-glucosidase

Glyco Hydrolase

Family $3 \mathrm{~N}$-Domain)
Glyco Hydrolase Family 3 C-Domain
$\mathrm{FN}-3$ like Domain 


\begin{tabular}{|c|c|c|}
\hline Gene (Putative function) & Function & e-value \\
\hline$\beta$-xylosidase & $\begin{array}{l}\text { Cleaves terminal } \beta-1,4 \text { bonds in xylose } \\
\text { polymers and hydrolyses xylobiose to } \\
\text { release D-xylose sugars. }\end{array}$ & $7.6 \times 10^{-157}$ \\
\hline Endo-1,4- $\beta$-xylanase & $\begin{array}{l}\text { Cleaves internal } \beta-1,4 \text { bonds in xylose } \\
\text { polymers to release shorter xylose } \\
\text { oligomers. }\end{array}$ & $8 \times 10^{-94}$ \\
\hline$\alpha$-L-Arabinofuranosidase & $\begin{array}{l}\text { Cleaves terminal non-reducing } \alpha \text {-L- } \\
\text { arabinofuranoside residues }\end{array}$ & $3.5 \times 10^{-94}$ \\
\hline$\beta$-Glucosidase & $\begin{array}{l}\text { Cleaves } \beta-1,4 \text { glycosidic bonds between } \\
\text { glucose dimers. }\end{array}$ & $2.1 \times 10^{-125}$ \\
\hline
\end{tabular}

\section{Hemicellulose (Simplified)}

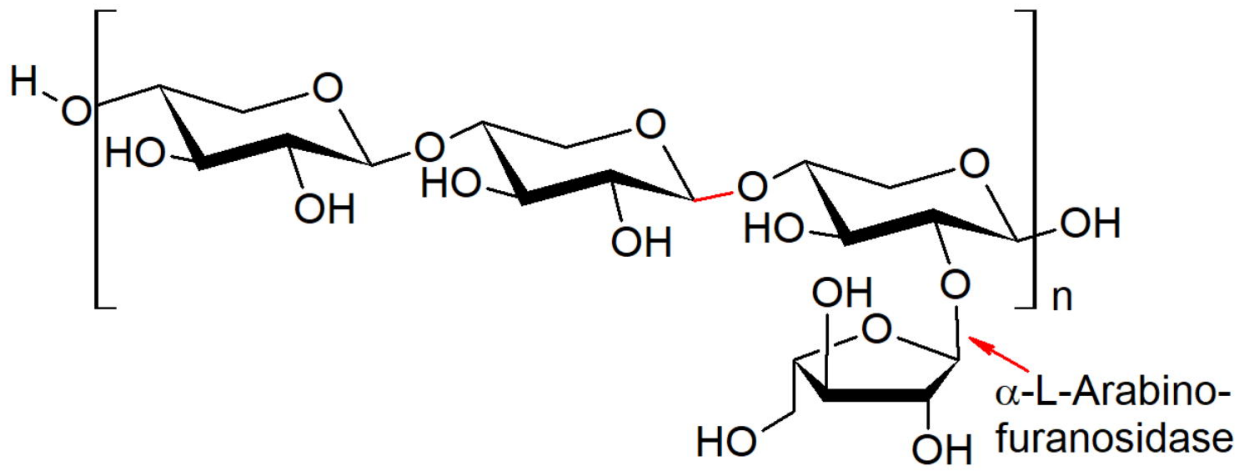

B

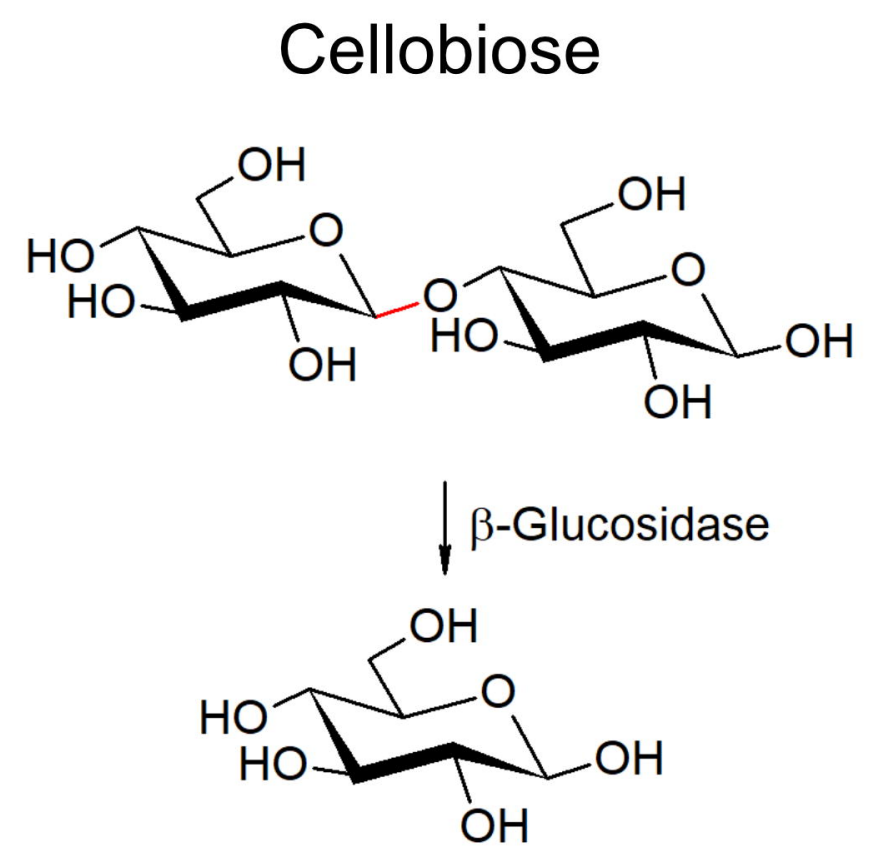



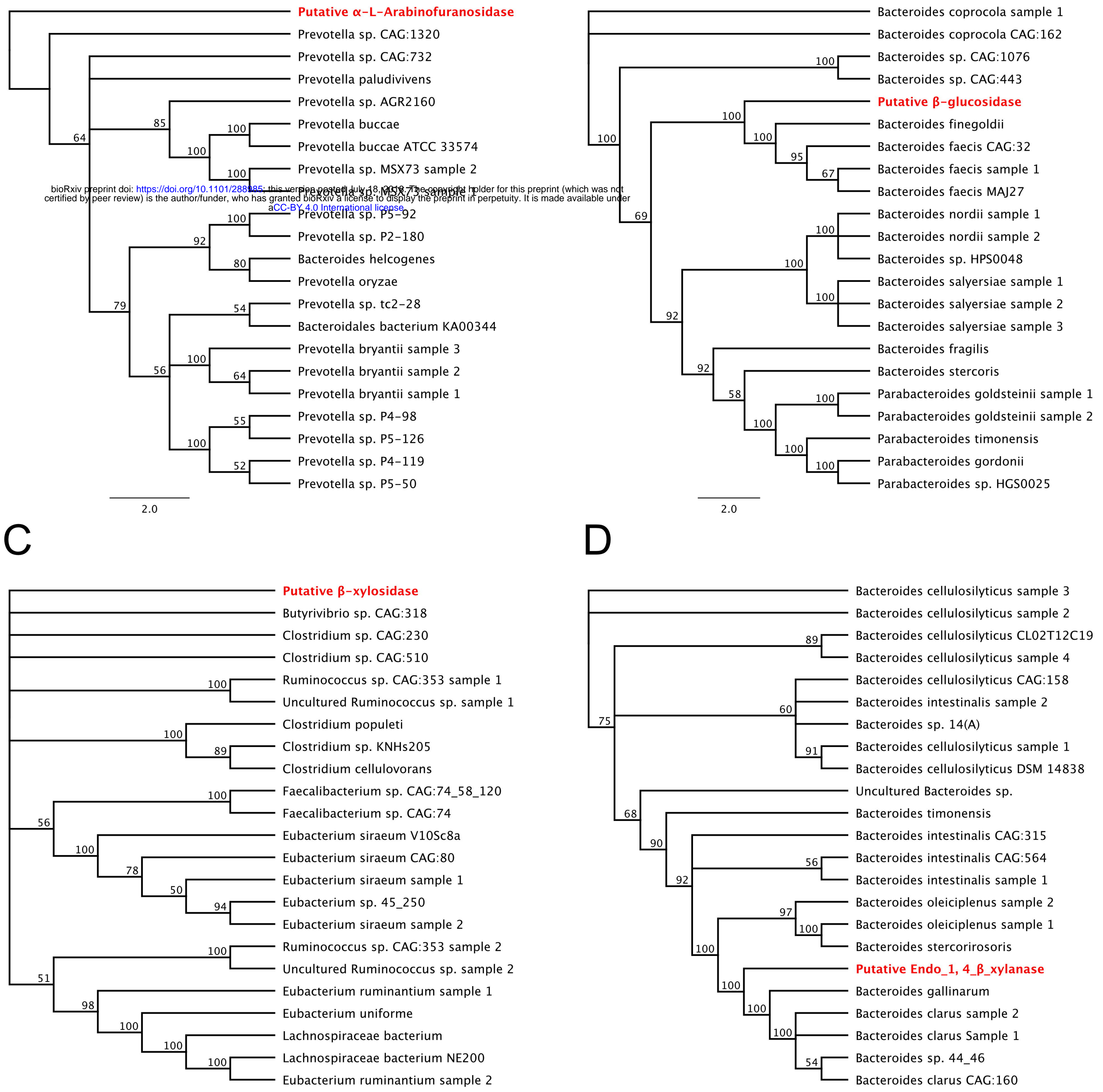
$100-$

80

$58-$

$46-$

$32-$

$25-$
8

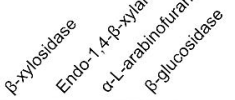

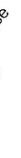

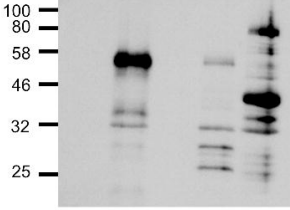

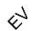
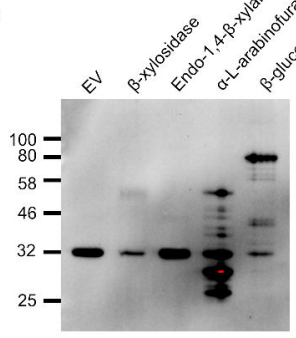
A

$\beta$-Glucosidase (81 kDa)

$\beta$-Glucosidase DesR ( 84 kDa)

\section{Putative $\beta$-Glucosidase Activity}

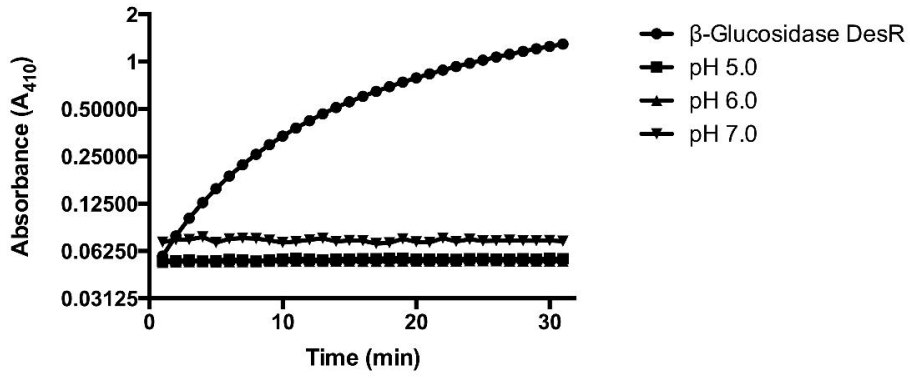




\section{Endo Xylanase (101 kDa)}

C

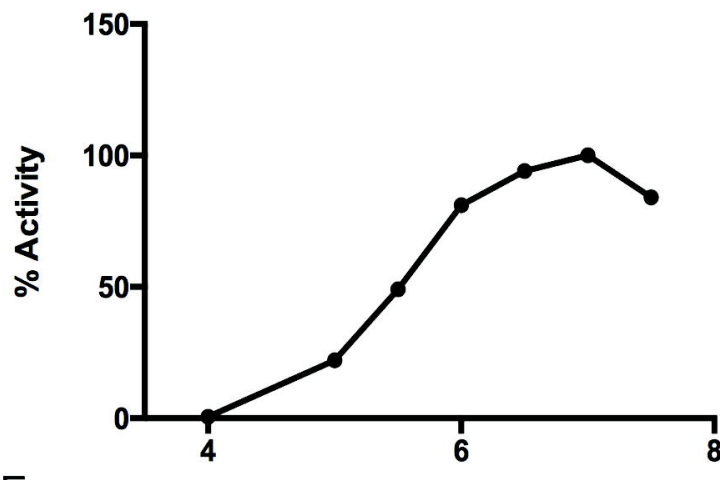

E

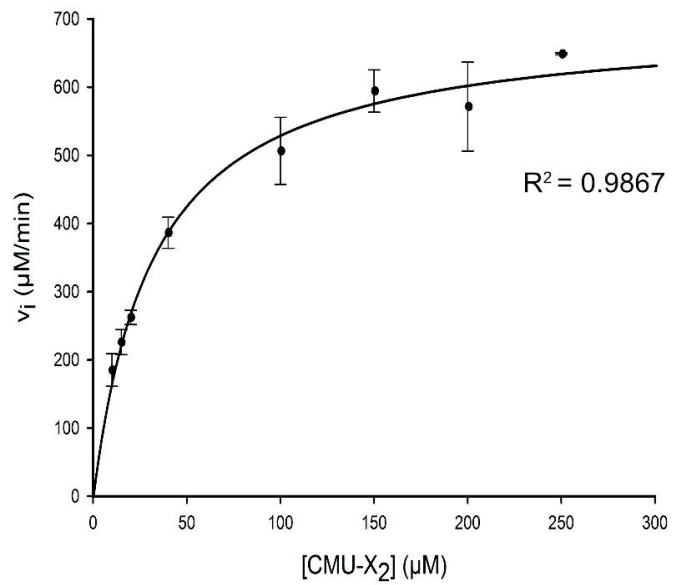

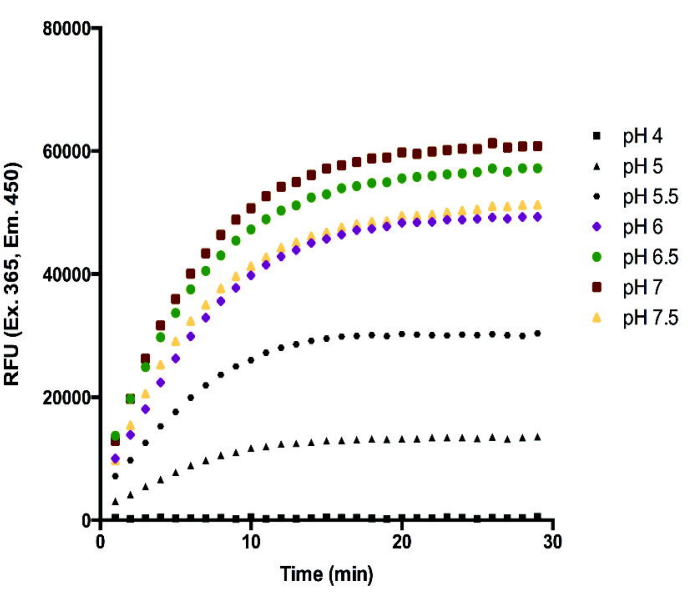

D

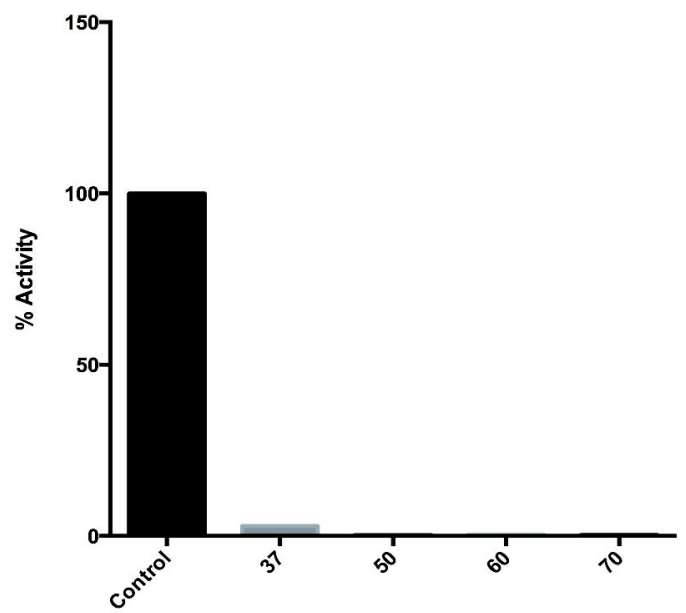

Temperature $\left({ }^{\circ} \mathrm{C}\right)$

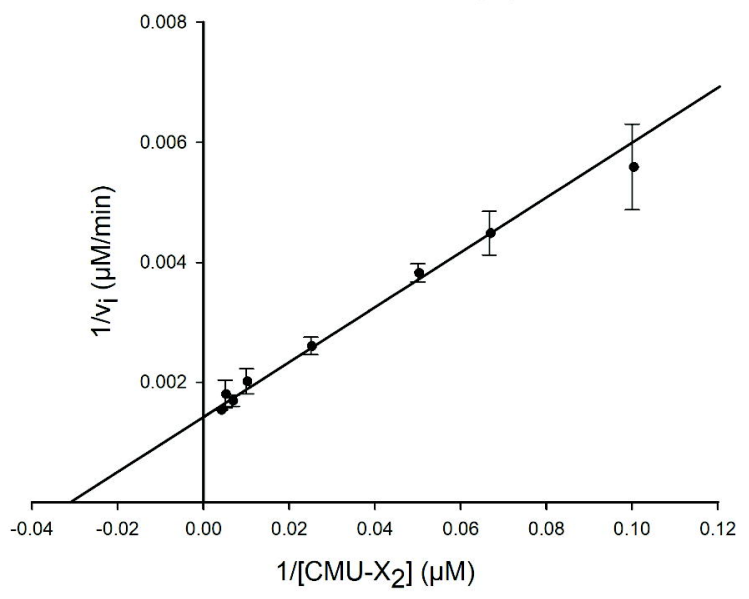

